University of New Haven

University of

New Haven

Digital Commons@ New Haven

Civil Engineering Faculty Publications

Civil Engineering

$8-2008$

\title{
Flexural Behavior of Reinforced Concrete Beams Strengthened with CFRP Sheets and Epoxy Mortar
}

Byong Y. Bahn

Daejeon University

Ronald S. Harichandran

University of New Haven, rharichandran@newhaven.edu

Follow this and additional works at: http://digitalcommons.newhaven.edu/civilengineering-facpubs Part of the Civil Engineering Commons

\section{Publisher Citation}

Bahn, B. Y., and Harichandran, R. S. (2008). "Flexural behavior of reinforced concrete beams strengthened with CFRP sheets and epoxy mortar." Journal of Composites for Construction, ASCE, 12(4), 387-395.

\section{Comments}

This is the authors' accepted version of the article published in Journal of Composites for Construction. The version of record can be found in the ASCE library at http://dx.doi.org/10.1061/(ASCE)1090-0268(2008)12:4(387) 


\title{
Flexural Behavior of Reinforced Concrete Beams Strengthened with CFRP Sheets and Epoxy Mortar
}

\author{
Byong Y. Bahn ${ }^{1}$ and Ronald S. Harichandran, ${ }^{2}$ F. ASCE
}

\section{CE DATABASE SUBJECT HEADINGS}

fiber reinforced polymers; reinforcement; anchorages; epoxy compounds; flexural strength; stiffness

\begin{abstract}
Experiments were conducted to study the effect of using epoxy mortar patch end anchorages on the flexural behavior of reinforced concrete beams strengthened with carbon fiber reinforced polymer (CFRP) sheets. More specifically, the effect of the end anchorage on strength, deflection, flexural strain, and interfacial shear stress were examined. The test results show that premature debonding failure of reinforced concrete beams strengthened with CFRP sheet can be delayed or

\footnotetext{
${ }^{1}$ Prof., Dept. of Architectural Eng., Daejeon University, Daejeon 300-716, Korea

2 Prof. and Chair, Dept. of Civil and Envir. Eng., Michigan State University, East Lansing, MI 48824-1226
} 
prevented by using epoxy mortar patch end anchorages. A modified analytical procedure for evaluating the flexural capacity of reinforced concrete beams strengthened with CFRP sheets and epoxy mortar end anchorage is developed and provides a good prediction of test results.

\section{INTRODUCTION}

In the last decade, fiber reinforced polymer (FRP) composites have been used for strengthening reinforced concrete (RC) structural members. External post-tensioning, bonding of steel plates, section enlargement, and total replacement have been the traditional methods used to enhance structural strength. Many researchers have found that bonding FRP is an efficient, reliable, and cost effective method of RC structural strengthening and rehabilitation (Ziraba et al. 1994). A large number of RC structures need strengthening or rehabilitation to address corrosion of steel reinforcement, poor concrete construction or quality, changes in intended use, or increase in loads.

There is a growing need for infrastructure rehabilitation worldwide. Problems associated with the bonding of steel plates and FRP sheets demand further research. Bonding steel plates has the disadvantages of corrosion over the long-term and difficult handling due to weight. Bonding FRP 
sheets has the advantages of high strength to weight ratio, lack of corrosion, and ease of constructibility.

More recently, FRP, and particularly, carbon fiber reinforced polymer (CFRP), have been used as an alternative to bonding steel plates (Rahimi and Hutchinson 2001). All FRP materials have linear elastic stress-strain behavior up to failure and have high tensile strength and failure strain. There is concern that these engineering characteristics may hinder the development of ductile flexural failure and the full utilization of the strength of the reinforcing material (Colotti et al. 2004). Ductility is desirable in structural design. Test results show that when steel plates are used as externally bonded reinforcement, the end anchorage details control the complex stress state of the plate end, and have a significant influence on the ductility of the strengthened beam (Jones et al. 1988).

Flexural strengthening of RC beams is one of the more challenging applications of FRP material. Extensive experimental and analytical research has been conducted on the flexural strength of concrete beams with various types of bonded FRP composites. There are four failure modes for RC beams strengthened with externally bonded FRP plates: (1) debonding failure, (2) FRP rupture, (3) compression failure, and (4) shear failure (Bonacci et al. 2001). Strengthened beams fail predominantly by debonding of the FRP from the concrete surface before the FRP 
ruptures (Brena and Marci 2004). High interfacial shear stress concentrations at the ends of the bonded external reinforcement causes FRP debonding or ripping of the concrete cover adjacent to conventional internal steel reinforcing bars. Although, various techniques such as the use of anchor bolts or adhesively bonded anchor plates have been employed to reduce debonding failure, approximately $60 \%$ of the beams tested in previous studies still showed debonding of the FRP or ripping of the concrete cover.

The experimental investigation reported in this paper is aimed at improving the debonding behavior in RC beams strengthened with CFRP sheets which have a practical and effective epoxy mortar anchorage. The study investigates the effect of CFRP strain, concrete-adhesive-CFRP interfacial shear stress, and cracking pattern of concrete on CFRP debonding and concrete cover ripping. Experimental and analytical results are presented for RC beams strengthened with CFRP sheets.

\section{EXPERIMENTAL PROGRAM}

\section{Test Beams}

Many experimental investigations have shown that premature failure can occur because of FRP debonding or ripping caused by interfacial shear stress concentrations at the ends of bonded 
FRP reinforcement (Colotti and Spadea 2001). In this study, epoxy mortar patches are applied at both ends of the CFRP bonded RC beam specimens to delay or prevent such premature debonding failures. Although many test variables could be examined, the principal test parameters in this study were limited to the anchorage type and method of applying the epoxy mortar. It was postulated that the epoxy mortar patch would resist the high concrete-adhesiveCFRP interfacial shear stress, and premature debonding failure would be delayed or eliminated due to the high bond strength of the epoxy mortar in the anchorage zone at the beam end.

Six anchorage types were designed to improve the performance of the $\mathrm{RC}$ beams strengthened with CFRP sheets and to compare the anchorage effect. The anchorage configurations are shown in Error! Reference source not found. and consist of; (1) epoxy mortar, (2) anchor bolt, (3) U-shaped CFRP, (4) anchor bolt + U-shaped CFRP, (5) flat bonding surface, and (6) wavy bonding surface. All anchorage types are applied on top of epoxy mortar patches in the end anchorage zone.

The RC beams were designed to have full flexural strength before and after being strengthened with CFRP sheets and within practical limitations. A total of eleven test specimens were prepared with three D10 bars on the bottom, two D10 bars on the top, and D6 stirrups spaced at $100 \mathrm{~mm}$. Three types of $2000 \mathrm{~mm}$ long RC beams having cross-sectional dimensions of 
$150 \mathrm{~mm} \times 250 \mathrm{~mm}$ were designed. All beams were cast from the same batch of ready-mixed normal concrete, and five concrete cylinders were also prepared. All RC beams were constructed in the laboratory using conventional curing techniques.

Table 1 shows the anchorage type for all beam specimens. The code used to identify each specimen consists of two letters and a number. The first letter is always a B denoting beams. The second letter $\mathrm{N}$ denotes specimens in which the epoxy mortar patch is not present. The second letter $\mathrm{F}$ designates specimens with epoxy mortar patches in the end anchorage zones. The letter $\mathrm{L}$ following the hyphen denotes beams strengthened with CFRP sheets. The number following the F is the length of the epoxy mortar patch. The letter U and A following the hyphen denote the anchorage types with $\mathrm{U}$ indicating a U-shaped CFRP anchor, A indicating an anchor bolt, and UA indicating the presence of both types of anchors.

Nine beam specimens had epoxy mortar patches in the anchorage zones, and additional anchorages were installed on the surface of the epoxy mortar. Expandable polystyrene was used to create cavities at the ends of beams, the polystyrene was removed after curing of the concrete, and the cavities were later filled with epoxy mortar. The BF1 series beams consisted of specimens with four different end anchorages: flat, U-shaped CFRP, anchor bolt, and U-shaped 
CFRP with anchor bolt. The BW1 series beams consisted of specimens with two different end anchorages: wave, and wave with U-shaped CFRP.

The beam test was conducted under four-point bending. For flexural strengthening, a CFRP sheet was bonded to the bottom of the beam with the fibers oriented along the length of the beam.

For the U-shaped anchor, a CFRP sheet was wrapped around three sides of the beam (excluding the top face) on top of the longitudinal CFRP reinforcement and the epoxy mortar patches at the beam ends. When used, anchor bolts were $110 \mathrm{~mm}$ long and fastened through pre-drilled holes at the ends of the concrete beam and CFRP reinforcement. Steel plates were used between the bolt heads and the CFRP.

\section{Material Properties}

Table 2 shows mechanical properties of the constituent materials: concrete, epoxy mortar, steel reinforcing bars, and CFRP sheets. The properties of the CFRP depend on the fiber type and resin, fiber content, fiber orientation, and manufacturing process. The properties of the CFRP sheet were obtained from the supplier. 


\section{Bonding of CFRP Sheets}

All beam specimens were strengthened for flexure using a unidirectional CFRP sheet applied using the wet-layup procedure with the fibers oriented parallel to the longitudinal axis of the beams. The CFRP sheets were bonded to the concrete beam specimens by the industrial field procedure for manual layup as follows: (1) the bottom faces of the beams were lightly ground, blown with air and partially coated with a putty; (2) a surface primer was applied; (3) the first layer of impregnating resin was applied; (4) the CFRP sheet was applied after removing its backing; and (5) the second layer of impregnating resin was applied and air trapped beneath the CFRP sheets was removed. After seven days of curing, the specimens were tested to failure.

\section{Flexural Test Procedure}

Electrical resistance wire strain gages (WSG) were bonded to the steel reinforcing bars at midspan before casting concrete. WSG also were installed on the external surfaces of the CFRP sheets along the length of the beams to measure the strain variation. Linear variable differential transducers (LVDTs) were installed to record deflections by means of a computerized data acquisition system. The locations of the LVDTs are shown in Error! Reference source not found.. The beams were subjected to a four point flexural bending test. An automatic data 
acquisition system was used to monitor loading, deflections, and strains on the CFRP sheets and the steel reinforcing bars. The load was applied stepwise to the beam by means of an MTS actuator system. At each load step, cracks were observed and marked.

\section{Observed Failure Patterns}

Typical crack patterns in the beam specimens after they failed are shown in Error! Reference source not found.. The control beam (BN) had a typical flexural failure, and beams (BN-L) strengthened with CFRP sheets and without mortar patches failed by debonding of the CFRP. Beams strengthened with CFRP and mortar patches, however, failed by CFRP sheet rupture, although some local debonding of CFRP sheets occurred before final failure. The failure location and failure mechanism of the CFRP varied according to the end anchorage type. The CFRP sheets started to fail after the beams reached the maximum load except for two beams (BN and BN-L).

The unstrengthened control beam BN exhibited a typical flexural failure similar to that of a conventional RC beam. The strengthened control beam without mortar patches (BN-L) failed by CFRP debonding due to interfacial shear stress concentration at the beam end, and local debonding also occurred due to concrete flexural cracking away from the ends. On the other hand, 
all other beams strengthened with CFRP and epoxy mortar patches failed by CFRP rupture accompanied by local debonding of the CFRP due to concrete flexural cracking and or interfacial shear stress away from the ends. The beam test was terminated after the CFRP debonded or ruptured. Beam BW1-L showed tensile failure of the CFRP just before the wavy surface anchorage at the beam end, and also displayed a tensile stress concentration in the strain measurements on the CFRP before the wavy surface anchorage. Beam BF2-LU exhibited CFRP rupture at midspan. All beam specimens with CFRP rupture were accompanied by local debonding of the CFRP due to crack propagation in the concrete as the applied load was increased.

\section{Strength of Test Beams}

A summary of the experimental results is presented in Table 3. This includes load and deflection at cracking, yield, and peak load, and the midspan displacement ductility factor, and principal failure mode. Yielding was defined as the stage of loading at which the measured strain in the steel reinforcement was 2000 micro-strain. The displacement ductility factor is defined as the ratio of midspan deflection at CFRP failure to midspan deflection at steel yield.

Initial cracking occurred at about the same load level for all beams. All beams strengthened 
with CFRP performed better than the control beam, in terms of strength and ductility. The strength of strengthened beams depends on the strain-stress properties of the constituent materials, and the strength of the adhesive bond between the CFRP and concrete. The performance of strengthened beams is influenced most by the anchorage method at the beam end. The maximum load of RC beams strengthened with CFRP is close to the load at which the CFRP ruptures.

The load-deflection curves for the beams are shown in Error! Reference source not found..

All beam specimens display linear elastic behavior at the beginning followed by a first crack within the constant moment region of the beam. Thereafter, the load-deflection curve becomes highly nonlinear as numerous flexural cracks develop and the beam deflection increases considerably. There was no noticeable differences in behavior for the beams with the mortar patch, anchor bolt and U-shaped CFRP anchorage types. The similarity in behavior implies that the overall load-deflection behavior of the strengthened beams is dominated by the effect of the mortar patch end anchorage. Thus, the mortar patch length is expected to play an important role in controlling the deflection and failure load in the test beams.

The control beam BN reached failure by yielding of the tensile steel reinforcement prior to crushing of the concrete. Specimen BN-L, which did not have epoxy mortar patches at the beam ends, failed by CFRP debonding at the concrete adhesive interface. The CFRP debonding started 
at flexural cracks in the constant moment region and propagated toward both beam ends until the entire CFRP debonded.

Error! Reference source not found. indicates that the failure load of RC beams strengthened with CFRP was enhanced on average by a factor of 1.38 with respect to the control beam BN. The ductility of strengthened beams was also improved on average by a factor of 1.43 with respect to the strengthened control beam BN-L. The ductility of beams with the wavy surface at the end anchorage zone is superior to the other special anchorage details considered in this study. It should be noted that the improvement of ductility is higher than the enhancement of failure load.

The failure load of beam specimens with any type of end anchorage is higher than the control beam without any end anchorage. The failure load of beams with anchor bolts or U-shaped FRP is slightly higher than that of the beams with mortar anchorage. In general, there is no significant difference in the failure load of beams strengthened with CFRP among the various end anchorage types and surface shapes. Thus, the failure load of strengthened beams is mainly enhanced by the mortar patch anchorage and not by the other anchorage details.

The ductility of all beams with the different anchorage types was enhanced with respect to the strengthened control beam. The ductility is improved slightly by using the anchor bolts and U- 
shaped FRP in addition to the mortar anchorage. The ductility of the BF1 series beams is superior to the BF2 series beams. Therefore, the wavy surface shape in the end anchorage zone improves ductility compared to the untextured flat surface. The ductility of the beam with the wavy surface is higher than that of the strengthened control beam by a factor of 1.78 .

\section{Stiffness of Test Beams}

The slopes of the curves in Error! Reference source not found. represent the stiffnesses

during the initial elastic, post-cracking and post-yield regions. The bonded external CFRP sheet does not contribute greatly to an increase in stiffness during the initial elastic range of the beams when no end anchorage is used. The flexural stiffness is enhanced in all three load-deflection regions (initial elastic, post-cracking, and post yield) when end anchorages are used. The flexural stiffness is increased by an average factor of 2.24 over the control beam in the initial elastic range, but was similar to that of the control beam (average factor of 1.04) in the post-cracking range.

The flexural stiffness in the post-yielding range for beams with end anchorages shows a sharp increase by an average factor of 3.64. Therefore, it can be concluded that end anchorages significantly enhance the flexural stiffness of the strengthened beams, and that the CFRP engages strongly in carrying load after the internal steel reinforcing bars yield. 


\section{Distribution of Flexural Strain in CFRP}

The distribution of flexural strain in the CFRP along the length of beams is shown in Error!

Reference source not found.. The locations of the maximum flexural strain are observed close to the midspan or loading points in all beam specimens. For the strengthened beams without mortar anchorage, the maximum flexural strain measured in the CFRP sheet was much lower than its ultimate strain of 0.01 , indicating an inefficient use of the material. The maximum flexural strains in the CFRP for all beam specimens with mortar anchorage are greater than those in beam BN-L which does not have mortar anchorage. It should be noted that the maximum strain gradient in the CFRP does not necessarily occur at midspan, or in the constant moment region along the beam specimens. The maximum strain gradient in the CFRP occurs at the end anchorage zone in the BF1 series beams and between the load points and end anchorage zones for the BF2 series beams. Thus, the CFRP strain gradient is influenced more by the mortar patch length than the anchorage type. The maximum strain gradient is more important in characterizing the failure behavior of the externally strengthened $\mathrm{RC}$ beam than the maximum flexural strain. The maximum strain differences are developed within the mortar patches for the BF1 series beams but at the inner end of the mortar patches for the BF2 series beams. The interfacial shear stress is directly 
proportional to the flexural strain gradient along the beam. Error! Reference source not found. therefore indicates that the location of the maximum interfacial shear stress is not always developed at the CFRP cutoff at the beam end but can change due to the better end anchorage of the CFRP as in the BF2 series beams.

Error! Reference source not found. shows that the maximum flexural strain in the CFRP increases progressively for the $\mathrm{BF} 1, \mathrm{BF} 2$, and wave series beams, respectively. This increase of flexural strain indicates that the maximum strain in the CFRP is influenced more by the surface shape at the end anchorage than the mortar patch length. The maximum CFRP strain in beams with the wavy surface is greater than for the BF1 series beams with the same mortar patch length. The maximum CFRP strain for the BF2 series beams, which have a mortar patch length twice that of the $\mathrm{BF} 1$ series beams, is greater than for the $\mathrm{BF} 1$ series beams.

The maximum CFRP strains for beams with mortar, anchor bolt, U-shaped CFRP, and Ushaped CFRP with anchor bolt anchorages are greater than for the strengthened control beam. The maximum CFRP strains for the BF2 series beams are higher than for the BF1 series beams. There is no noticeable difference in the maximum CFRP strain for beams with different anchorage methods. This implies that the mortar anchorage is the dominant variable influencing the maximum flexural CFRP strain. 
The load-CFRP strain distributions are shown in Error! Reference source not found. for the BF1-LA beam which has additional anchorage at the beam end. The CFRP strain increased uniformly at all locations along the beam up to a load of $62.41 \mathrm{kN}$, and the strain increase spread toward the beam ends until the CFRP ruptured. The CFRP strain shows a tremendous increase at the beam end as the applied load approaches the CFRP rupture load. A decrease in CFRP strain with increasing applied load indicates that strain release is occurring at the corresponding location of the beam. Strain release occured at the maximum load at midspan. Thus, CFRP debonding must initiate at midspan and propagate toward the support. Although the maximum CFRP strain gradient occurred at the beam end, there is no noticeable strain release at the ends during the whole loading stage because of the effective anchorage. Thus, it can be concluded that the mortar anchorage is very effective in improving the bond behavior of strengthened beams to delay or prevent premature debonding of the CFRP.

Error! Reference source not found. shows that the location of the maximum strain gradient during the early loading stage occurred near the one-third span points, and this location moved toward the beam ends as the applied load increased. Therefore, it is evident that the location of the maximum interfacial shear stress shifts from the one-third span to the end of the beam as the applied load is increased. Load-strain distributions at each loading stage (Error! Reference 
source not found.) can therefore be used effectively to detect debonding by observing the correspond release in the CFRP strain.

\section{Variation of Interfacial Shear Stress}

The concrete-adhesive-CFRP interfacial shear stress can be obtained from experimental test data by realizing that the force in the bonded external plate must equal the shear force exerted by the adhesive layer between the concrete substrate and the external plate (Alagusundaramoorthy et al. 2003). This may be expressed in the following mathematical form:

$$
E_{p} b_{p} t_{p} \Delta \varepsilon=\tau_{a} \Delta L b_{a}
$$

where, $E_{p}=$ elastic modulus of CFRP, $b_{p}=$ width of CFRP, $t_{p}=$ thickness of CFRP, $\Delta \varepsilon=$ strain gradient along the beam, $\tau_{a}=$ concrete-adhesive-CFRP interfacial shear stress, $\Delta L=$ distance between measured strains, and $b_{a}=$ width of adhesive.

This yields:

$$
\tau_{a}=(\Delta \varepsilon / \Delta L) E_{p} t_{p}
$$

The distribution of interfacial shear stress along the length of the beam is shown in Error!

Reference source not found.. In conventional FRP reinforced beams the interfacial shear stress is largest at the ends of the plate and rapidly decreases when moving toward the midspan of the 
beam. However, this not the case for the beams with epoxy mortar patches. The maximum interfacial shear stresses for both BF1 and BW1 series beams which had mortar patch lengths of $250 \mathrm{~mm}$ occurred at the beam end, but those for the BF2 series which had $500 \mathrm{~mm}$ patch lengths occurred near the one-third span. Thus, it is evident that the location of the maximum interfacial shear stress is influenced more by the mortar patch length than the other anchorage details.

The distribution of the interfacial shear stress in the BF1 and BW1 series beams is similar to that of the conventionally strengthened RC beams. Many existing analytical models for the evaluation of the maximum interfacial shear stress or failure load are based on the assumption that the maximum interfacial shear stress occurs at the end anchorage zone of the beam. However, the distribution of shear stress in the BF2 series beams is different from that in conventionally strengthened beams because the maximum shear stress occurs near the one-third span. Thus, a new analytical model to predict the maximum interfacial shear stress or failure load is required to estimate the test results obtained in this study. Furthermore, since the shear stress concentration for the BF2 series is higher than for the BF1 series, it is believed that there should be an optimum mortar patch length for the anchorage that minimizes the shear stress concentration.

Error! Reference source not found. shows the effect of anchorage type and surface shape on the maximum interfacial shear stress. It shows that the maximum interfacial shear stress is not 
very sensitive to the anchorage type. Therefore, the interfacial shear stress depends mostly on the mortar anchorage. The beams with mortar patch anchorage are able to sustain higher interfacial shear stresses than the strengthened control beam BN-L which does not have mortar anchorage. Further, the BF2 series beams sustained higher interfacial shear stresses than the BF1 series. The effect of surface shape of the anchorage on the average sustained maximum interfacial shear stress (Error! Reference source not found.(b)) shows a linear enhancement in proportion to the mortar patch length (FLAT-2 vs. FLAT-1), and that the waved surface is superior to the flat surface for the same mortar patch length.

In conclusion, the influence of the flat surface anchorage type on the sustained interfacial shear stress is similar for the anchor bolt, U-shaped FRP, and mortar anchorages. Thus, the anchorage with the strongest influence on the sustained interfacial shear stress is the mortar patch. Increasing the mortar patch length improves the interfacial shear strength, and the waved surface further improves the mortar anchorage.

\section{ANALYTICAL STUDY}

The nonlinear behavior of concrete under load is frequently dominated by progressive cracking, resulting in localized failure. Extensive test and analytical studies of RC beams 
strengthened with externally bonded FRP reinforcement have indicated that the debonding of FRP plates is due to high local shear stresses at the ends of the plates, and that such delamination can be prevented by limiting the maximum stresses in the adhesive layer (Colotti et al. 2004). Roberts (1989) and Quantrill et al. (1996) have also suggested that ripping of the concrete cover can similarly be prevented by limiting the maximum stresses in the adhesive layer.

When CFRP laminates are used as externally bonded reinforcement, many tests show that FRP plate debonding and premature failure occur well before the full flexural capacity of the beam is reached (Colotti et al. 2004). Quantifying the debonding failure load for such beams is complicated and difficult.

A number of analytical studies have been conducted to explain steel or FRP plate debonding phenomenon (Teng et al. 2002 and Oehlers and Seracino 2004). Most studies are based on linear elastic material properties, and failure can occur in several modes. A common failure mode involves peeling of the FRP at the ends. However, the debonding failure loads from the various models are not always consistent, and have been validated using results only from experiments conducted on strengthened beams with conventional end anchorage methods.

Roberts (1989) proposed an approximate analytical method to predict the bond shear strength of RC beams strengthened with an externally bonded steel plate. Failure of RC beams 
strengthened with CFRP sheets is more difficult to analyze, because the failure is influenced by the epoxy thickness and mechanical properties, preparation of the concrete substrate, anchorage at CFRP plate ends, and propagating concrete cracks. The end anchorage plays a significant role on the behavior of the strengthened RC beam (El-Mihilmy and Tedesco 2001).

An analytical model to predict the FRP-adhesive-concrete interfacial shear strength is developed herein. Error! Reference source not found. shows an element of the external FRP plate subjected to resultant axial force and shear force per unit length due to the applied load. The interfacial shear stress in the adhesive layer can be determined from a two stage analysis. The bending stiffness of the RC section is much greater than that of the CFRP plate and hence the bending moment in the CFRP plate can be neglected. This implies that the normal stress in the adhesive layer can be neglected. The interfacial shear stress in the adhesive layer is therefore equal to the shear stress in the concrete at the level of the adhesive, and can be obtained from conventional beam theory and the solution of the governing differential equilibrium equation for the CFRP plate element. The failure load may be determined analytically from the maximum interfacial shear stress (Roberts 1989).

Based on the results reported herein, the anchorage method with the greatest influence on the strain and shear stress distribution in RC beams strengthened with CFRP is the mortar anchorage. 
Thus, the mortar patch length to the shear span ratio was employed as the primary parameter to modify Roberts's model to predict the maximum interfacial shear stress. The empirical modified model is able to consider both the debonding failure and the CFRP rupture. The modified analytical model for the failure load of RC beams strengthened with both CFRP and the end anchorages used in this work is:

$$
P=\frac{2 \tau_{o}}{C_{a}\left[1+\left(\frac{K_{s}}{E_{p} b_{p} t_{p}}\right)^{1 / 2}\left(L_{o}+\frac{h_{c}+t_{p}}{2}\right)\right] \frac{b_{p} t_{p}}{I b_{a}}\left(h_{p}-h\right)}
$$

where, $\quad C_{a}=0.939\left(L_{e} / a\right)+1.12$, if $L_{e}=0$ then $C_{a}=1.0$

$\tau_{o}=$ Maximum interfacial shear stress

$L_{e}=$ Mortar patch length,$a=$ Shear span

\section{COMPARISON OF ANALYTICAL AND EXPERIMENTAL RESULTS}

Failure loads predicted by Roberts's model and the modified model in Eq. (3) for the beams tested in this work are given in Table 4. Roberts's model accurately predicts the failure load for the BN-L beam which does not have end anchorages. However, it significantly overestimates the failure load for the beams strengthened with both CFRP and epoxy mortar end anchorage. The original model was developed to predict the maximum interfacial shear stress for conventionally strengthened beams, but the shear stress and its distribution is different for beams strengthened 
with the new mortar anchorage at beam end. Roberts's model yields poorer results for the BF2 series beams than for the BF1 series beams, because the maximum interface shear stresses for the BF1 series beams occurred at the beam ends as for conventionally strengthened beams, but for the BF2 series beams it occurred near the one-third spans. Such behavior in the interfacial shear stress was never observed in previous experimental studies. Thus, Roberts's model is only able to accurately predict the failure load of conventionally strengthened beams which have no special end anchorage details.

The failure load predicted by the modified analytical model in Eq. (3) shows good agreement with the experimental results. Thus, the modified model is able to consider the effects of anchorage type and epoxy mortar patches at the end anchorage zone for RC beams strengthened with CFRP. However, since the beams tested are small, additional large-scale beam tests should be performed to ascertain if any scale effects are introduced. Also, a limitation of the current work is that the data from this study is used to both calibrate and validate the proposed model. Since no other studies have been performed using epoxy mortar end anchorage, there is no other data at present that can be used to validate the model. 


\section{SUMMARY AND CONCLUSIONS}

Results from an experimental study conducted to investigate the effect of end anchorages on

the flexural behavior of RC beams strengthened with CFRP sheets are reported. The influence of the end anchorages on strength, deflection, flexural strain, interfacial shear stress, and failure load are documented. The test results show that the premature debonding failure in $\mathrm{RC}$ beams strengthened with CFRP sheets can be delayed or prevented by using epoxy mortar patch end anchorages thereby enhancing flexural performance. A modified analytical equation for predicting the flexural capacity of RC beams strengthened with CFRP and including end anchorages is presented.

The mortar patch anchorage used in this experimental study is very effective in delaying or preventing the premature debonding failure that is the dominant failure mode for beams conventionally strengthened with CFRP. Mortar cover failure at the interface between the adhesive and the mortar patch did not occur due to the high tensile strength of the epoxy mortar.

Providing a wavy surface to the mortar patch improves the bond between the CFRP and the patch compared to the bond for a flat surface. The mortar patch length is the most influential parameter that improves the interfacial shear strength for RC beams strengthened with CFRP sheets. 
End anchorage details in addition to the mortar patch (such as anchor bolts, U-shaped CFRP, and wavy surface) do not significantly increase flexural strength any further. The ductility of beams with a waved surface at the end anchorage zone is superior to those with the other special anchorage details used in this study.

Since the mortar anchorage is the most influential anchorage affecting both the maximum interfacial shear strength and the failure load, the mortar patch length to shear span ratio was employed as the primary parameter to modify Roberts's model for predicting the failure load of RC beams strengthened with CFRP and mortar patch anchorages. The modified model provides good accuracy.

\section{ACKNOWLEDGMENTS}

The authors are grateful to Hankuk Carbon Co. for donating the composite materials used in this study.

\section{NOTATION}

The following symbols are used in this paper:

$C_{a}=$ primary modification factor for failure load prediction 
$I=$ transformed moment of inertia of cracked section including CFRP plate

$L_{e}=$ length of epoxy mortar patch

$L_{o}=$ distance from support to CFRP end

$E_{p}=$ elastic modulus of CFRP

$K_{s}=$ shear stiffness per unit length of adhesive layer along the beam

$a=$ shear span

$b_{a}=$ width of adhesive layer

$b_{p}=$ width of carbon fiber reinforced polymer plate

$h=$ neutral axis depth

$h_{c}=$ height of concrete beam

$h_{p}=$ effective depth of longitudinal CFRP

$t_{p}=$ thickness of CFRP

$\Delta \varepsilon=$ difference in flexural strain along the beam

$\Delta L=$ distance between measured strain

$\tau_{a}=$ concrete-adhesive-CFRP interfacial shear stress

$\tau_{o}=$ maximum interfacial shear stress 


\section{REFERENCES}

Alagusundaramoorthy P., Harik I. E., and Choo C. C. (2003). "Flexural behavior of R/C beams strengthened with carbon fiber reinforced polymer sheets or fabric.” J. Compos. Constr., 7(4), 292-301, November.

Bonacci J. F., and Maalej M. (2001). "Behavioral trends of RC beams strengthened with externally bonded FRP.” J. Compos. Constr., 5(2), 102-113, May.

Brena S. F., and Marci B. M., (2004). "Effect of carbon-fiber-reinforced polymer laminate configuration on the behavior of strengthened reinforced concrete beams." J. Compos. Constr., 8(3), 229-240, May/June.

Colotti, V., and Spadea G.. (2001). "Shear strength of RC beams strengthened with bonded steel or FRP plates.” J. Struct. Eng., 127(4), 367-373, April.

Colotti V., Spadea G.., and Swamy R. N. (2004). "Structural model to predict the failure behavior of plated reinforced concrete beams." J. Compos. Constr., 8(2), 104-122, March/April.

El-Mihilmy, M. T., and Tedsco J. W. (2001). "Prediction of anchorage failure for reinforced concrete beams strengthened with fiber-reinforced polymer plates.” ACI Struct J., 98(3), 301314, May/June. 
Oehlers, D. J., and Seracino, R. (2004). Design of FRP and steel plated RC structures. Elsevier Press, London.

Rahimi, H., and Hutchinson A. (2001). "Concrete beams strengthened with externally bonded FRP plates.” J. Compos. Constr., 5(1), 44-56, February.

Roberts, T. M. (1989). "Approximate analysis of shear and normal stress concentrations in the adhesive layer of plated RC beams." The Structural Engineer, 67(12), 229-233, June.

Teng, J. G., Chen, J. F., Smith, S. T., and Lam, L. (2002). FRP strengthened RC structures. Wiley, New York.

Ziraba, Y. N., Baluch, M. H., Basunbul, I. A., Sharif, A. M., Azad, A. K., and Al-Sulaimani, G. J. (1994). "Guidelines toward the design of reinforced concrete beams with external plates." ACI Structural J., 91(6), 639-646, Nov/Dec. 
Table 1. Description of Beam Specimen

\begin{tabular}{|c|c|c|c|c|c|}
\hline Beam & $\begin{array}{l}\text { Surface } \\
\text { Shape }\end{array}$ & $\begin{array}{l}\text { Mortar } \\
\text { Length }\end{array}$ & $\begin{array}{l}\text { CFRP } \\
\text { Ply }\end{array}$ & $\begin{array}{c}\text { Anchorage } \\
\text { Type }\end{array}$ & Remarks \\
\hline $\mathrm{BN}$ & - & - & - & - & $\begin{array}{c}\text { Unstrengthened } \\
\text { Control }\end{array}$ \\
\hline BN-L & - & - & \multirow{10}{*}{1} & - & $\begin{array}{l}\text { Strengthened } \\
\text { Control }\end{array}$ \\
\hline BF1-L & \multirow{7}{*}{ Flat } & \multirow{4}{*}{$250 \mathrm{~mm}$} & & - & \\
\hline BF1-LA & & & & Anchor bolts & Anchor 8 EA \\
\hline BF1-LU & & & & U-shaped CFRP & \\
\hline BF1-LUA & & & & $\begin{array}{c}\text { U-shaped CFRP+ } \\
\text { Anchor bolts }\end{array}$ & Anchor 8 EA \\
\hline BF2-L & & \multirow{3}{*}{$500 \mathrm{~mm}$} & & - & \\
\hline BF2-LA & & & & Anchor bolts & Anchor 8 EA \\
\hline BF2-LU & & & & U-shaped CFRP & \\
\hline BW1-L & \multirow{2}{*}{ Wave } & \multirow{2}{*}{$250 \mathrm{~mm}$} & & - & \\
\hline BW1-LU & & & & U-shaped CFRP & \\
\hline
\end{tabular}


Table 2. Mechanical Properties of Materials

\begin{tabular}{c|c|c|c|c}
\hline Material & Concrete & Rebar & CFRP & Epoxy \\
Property & & & & Mortar \\
\hline \hline Compressive Strength (MPa) & 24.3 & - & - & 102.1 \\
\hline Design Tensile Strength (MPa) & - & 559 & 3,481 & 15.2 \\
\hline Design Young's Modulus (MPa) & - & $1.96 \times 10^{5}$ & $2.3 \times 10^{5}$ & 10,342 \\
\hline Yield Strength (MPa) & - & 427 & - & - \\
\hline Tensile Strength (MPa) & - & - & 38.2 & - \\
\hline
\end{tabular}


Table 3. Summary of Test Results

\begin{tabular}{|c|c|c|c|c|c|c|c|c|c|}
\hline \multirow{2}{*}{ Beam } & \multirow{2}{*}{$\begin{array}{c}\text { Cracking } \\
\text { Load } \\
P_{c r} \\
(\mathrm{kN})\end{array}$} & \multicolumn{2}{|c|}{ Yield Load } & \multicolumn{2}{|c|}{ Maximum Load } & \multicolumn{2}{|c|}{ CFRP Failure Load } & \multirow{2}{*}{$\begin{array}{c}\text { Ductility } \\
\delta_{f} / \delta_{y}\end{array}$} & \multirow{2}{*}{$\begin{array}{l}\text { Failure } \\
\text { Mode }^{*}\end{array}$} \\
\hline & & $\begin{array}{c}P_{y} \\
(\mathrm{kN})\end{array}$ & $\begin{array}{c}\delta_{y} \\
(\mathrm{~mm})\end{array}$ & $\begin{array}{c}P_{u} \\
(\mathrm{kN})\end{array}$ & $\begin{array}{c}\delta_{u} \\
(\mathrm{~mm})\end{array}$ & $\begin{array}{c}P_{f} \\
(\mathrm{kN})\end{array}$ & $\begin{array}{c}\delta_{f} \\
(\mathrm{~mm})\end{array}$ & & \\
\hline $\mathrm{BN}$ & 9.61 & 41.50 & 6.17 & 53.45 & 46.49 & N.A. & N.A. & N.A. & Flexure \\
\hline BN-L & 14.32 & 54.23 & 7.16 & 67.96 & 22.02 & 67.86 & 22.36 & 3.12 & I \\
\hline BF1-L & 15.10 & 51.78 & 7.05 & 71.88 & 29.64 & 71.69 & 29.96 & 4.25 & II \\
\hline BF1-LA & 15.98 & 50.50 & 6.47 & 72.37 & 30.04 & 72.37 & 30.10 & 4.65 & II \\
\hline BF1-LU & 15.85 & 50.31 & 6.43 & 72.22 & 26.31 & 71.98 & 26.33 & 4.10 & II \\
\hline BF1-LUA & 17.85 & 53.25 & 6.42 & 76.79 & 31.44 & 76.79 & 31.44 & 4.90 & II \\
\hline BF2-L & 16.28 & 51.29 & 5.60 & 72.18 & 19.47 & 72.08 & 19.56 & 3.49 & II \\
\hline BF2-LA & 16.67 & 52.96 & 5.94 & 76.49 & 23.05 & 76.49 & 23.05 & 3.88 & II \\
\hline BF2-LU & 16.38 & 53.45 & 5.88 & 77.28 & 22.16 & 77.28 & 22.73 & 3.87 & II \\
\hline BW1-L & 14.51 & 49.62 & 6.31 & 71.69 & 36.36 & 70.71 & 36.37 & 5.76 & $\Pi$ \\
\hline BW1-LU & 15.40 & 51.98 & 6.09 & 76.98 & 32.66 & 76.98 & 32.66 & 5.36 & II \\
\hline
\end{tabular}

* I : CFRP Debonding; II : CFRP Rupture 
Table 4. Comparison of Analytical and Experimental Failure Loads

\begin{tabular}{c|c|c|c|c|c}
\hline Beam & $P_{\exp }$ & $P_{\text {rob }}$ & $P_{\text {mod }}$ & $P_{\text {rob }} / P_{\exp }$ & $P_{\text {mod }} / P_{\text {exp }}$ \\
\hline \hline BN & - & - & - & & \\
\hline BN-L & 67.96 & 68.14 & 68.14 & 1.00 & 1.00 \\
\hline BF1-L & 71.88 & 105.73 & 73.94 & 1.47 & 1.03 \\
\hline BF1-LA & 72.37 & 105.73 & 73.94 & 1.46 & 1.02 \\
\hline BF1-LU & 72.22 & 91.63 & 64.08 & 1.27 & 0.89 \\
\hline BF1-LUA & 76.79 & 98.68 & 69.01 & 1.29 & 0.90 \\
\hline BF2-L & 72.18 & 140.97 & 81.02 & 1.95 & 1.12 \\
\hline BF2-LA & 76.49 & 129.22 & 74.27 & 1.69 & 0.97 \\
\hline BF2-LU & 77.28 & 122.17 & 70.22 & 1.58 & 0.91 \\
\hline BW1-L & 71.69 & 115.13 & 80.51 & 1.61 & 1.12 \\
\hline BW1-LU & 76.98 & 115.13 & 80.51 & 1.50 & 1.05 \\
\hline
\end{tabular}



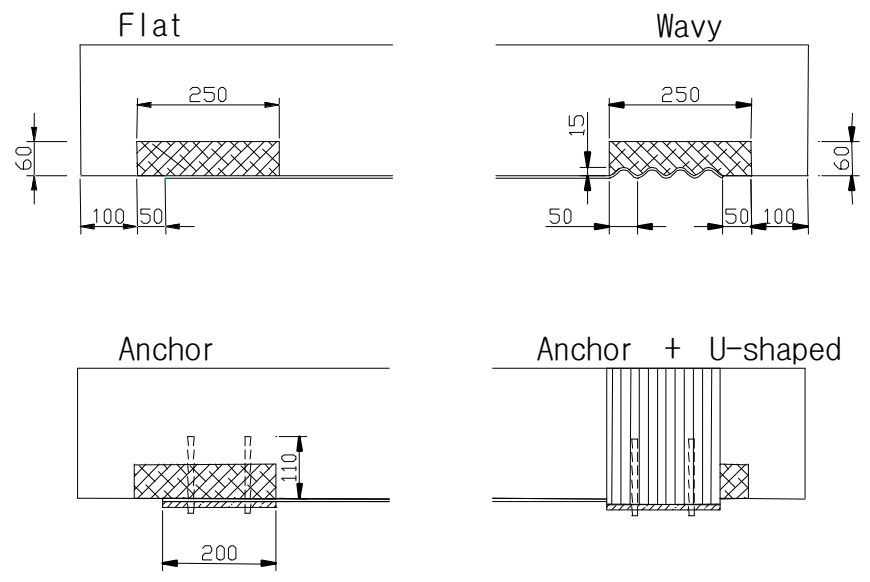

Figure 1. Anchorage Configurations with Mortar Patches 


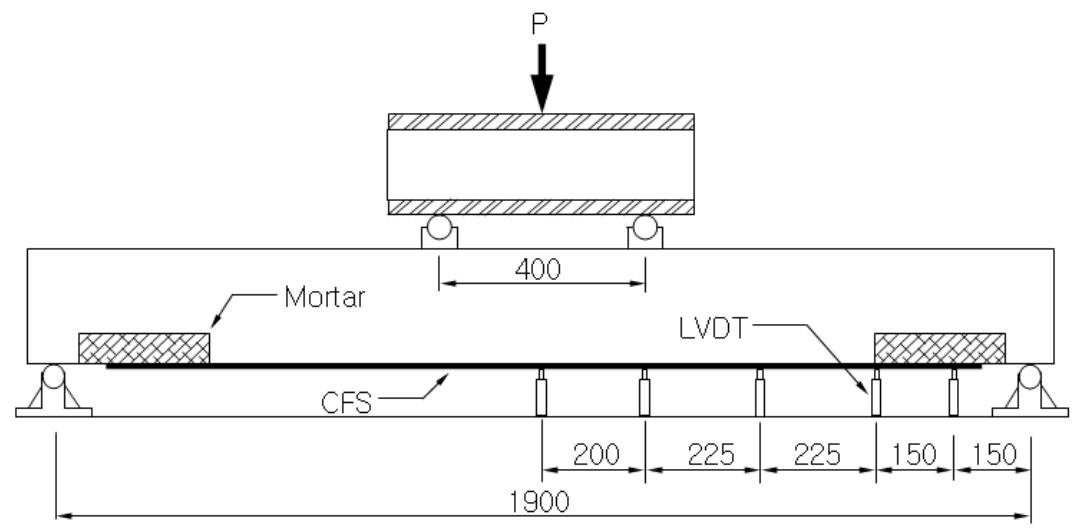

Figure 2. Test Set-up 


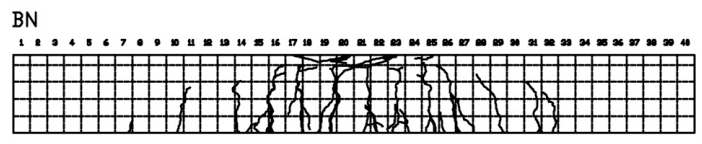

$\mathrm{BN}-\mathrm{L}$

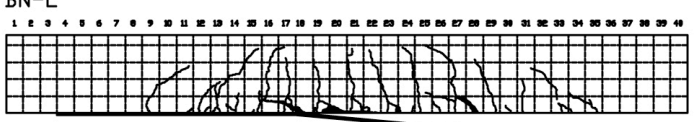

BF1-L

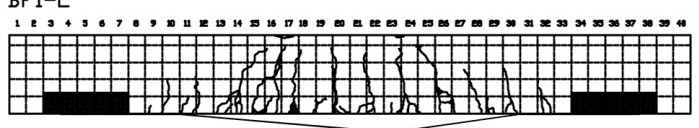

BF1-LA

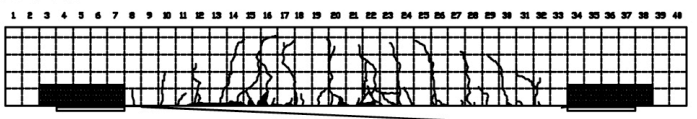

BF1-LU

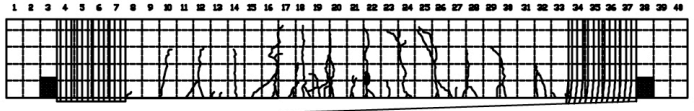

BF1-LUA

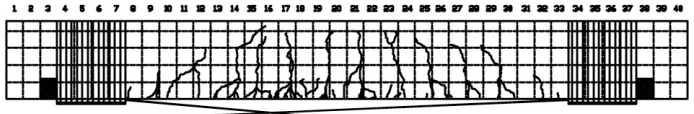

BF2-L

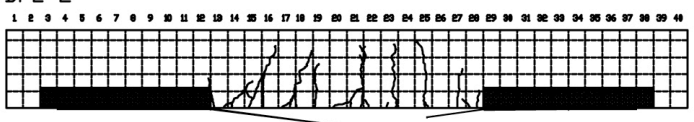

BF2-LA

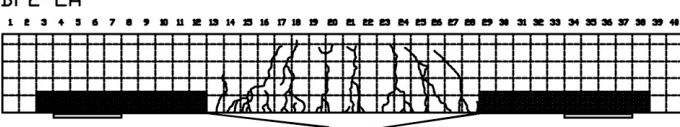

BF2-LU

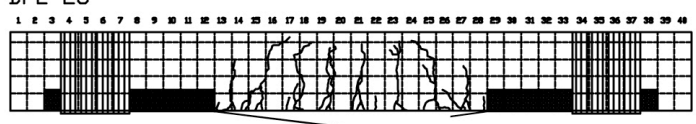

BW1-L

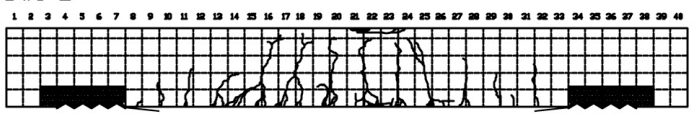

BW1-LU

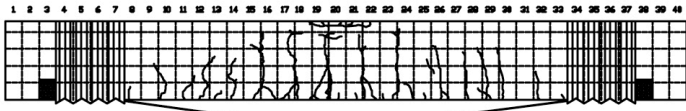
-

Figure 3. Crack Patterns at Failure 


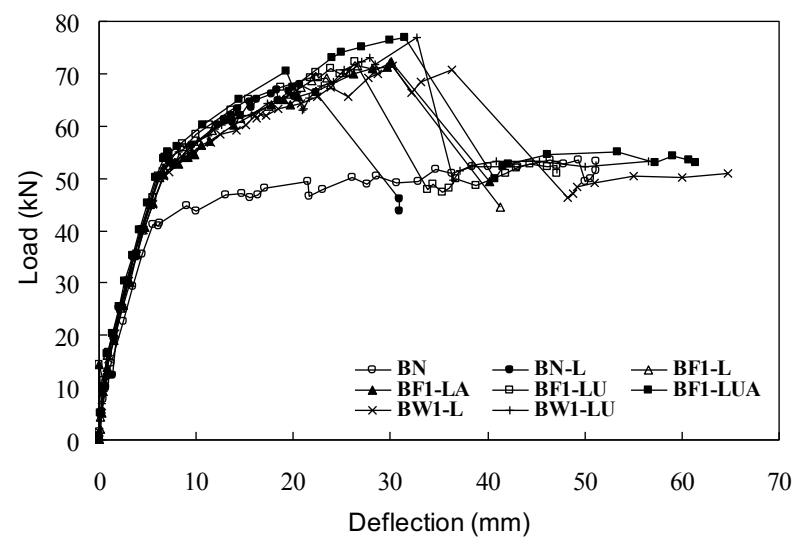

(a) BF1 Series Beams

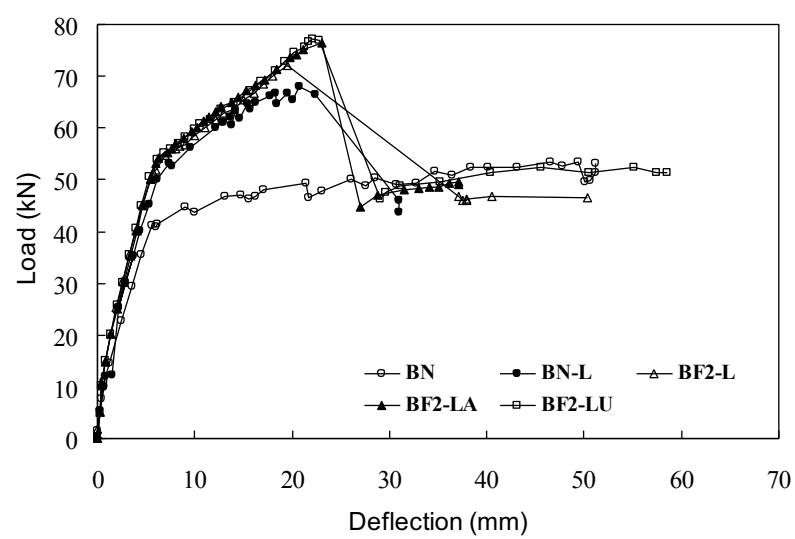

(b) BF2 Series Beams

Figure 4. Load-Midspan Deflection Curve 


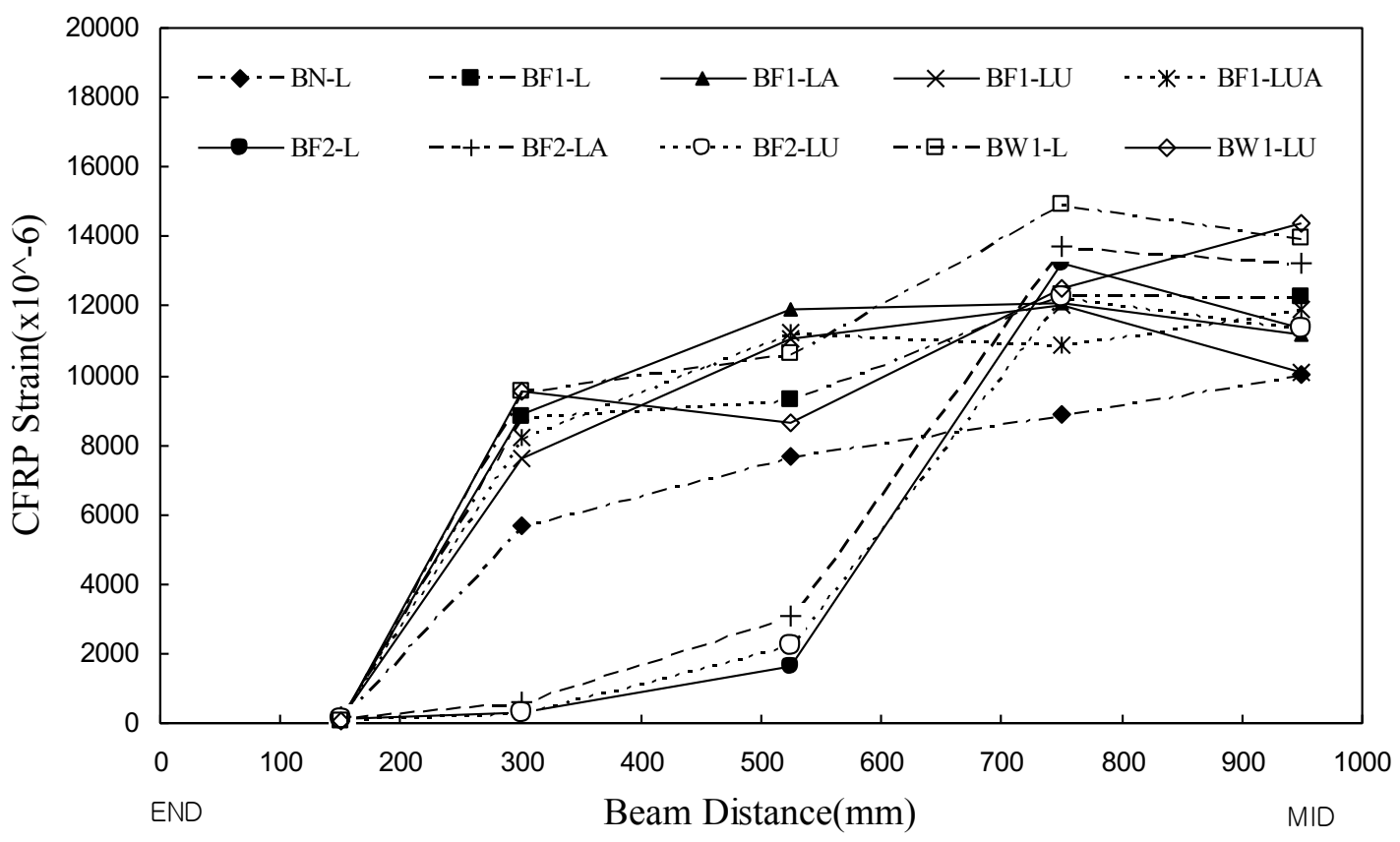

Figure 5. Distribution of CFRP Flexural Strain at Failure 


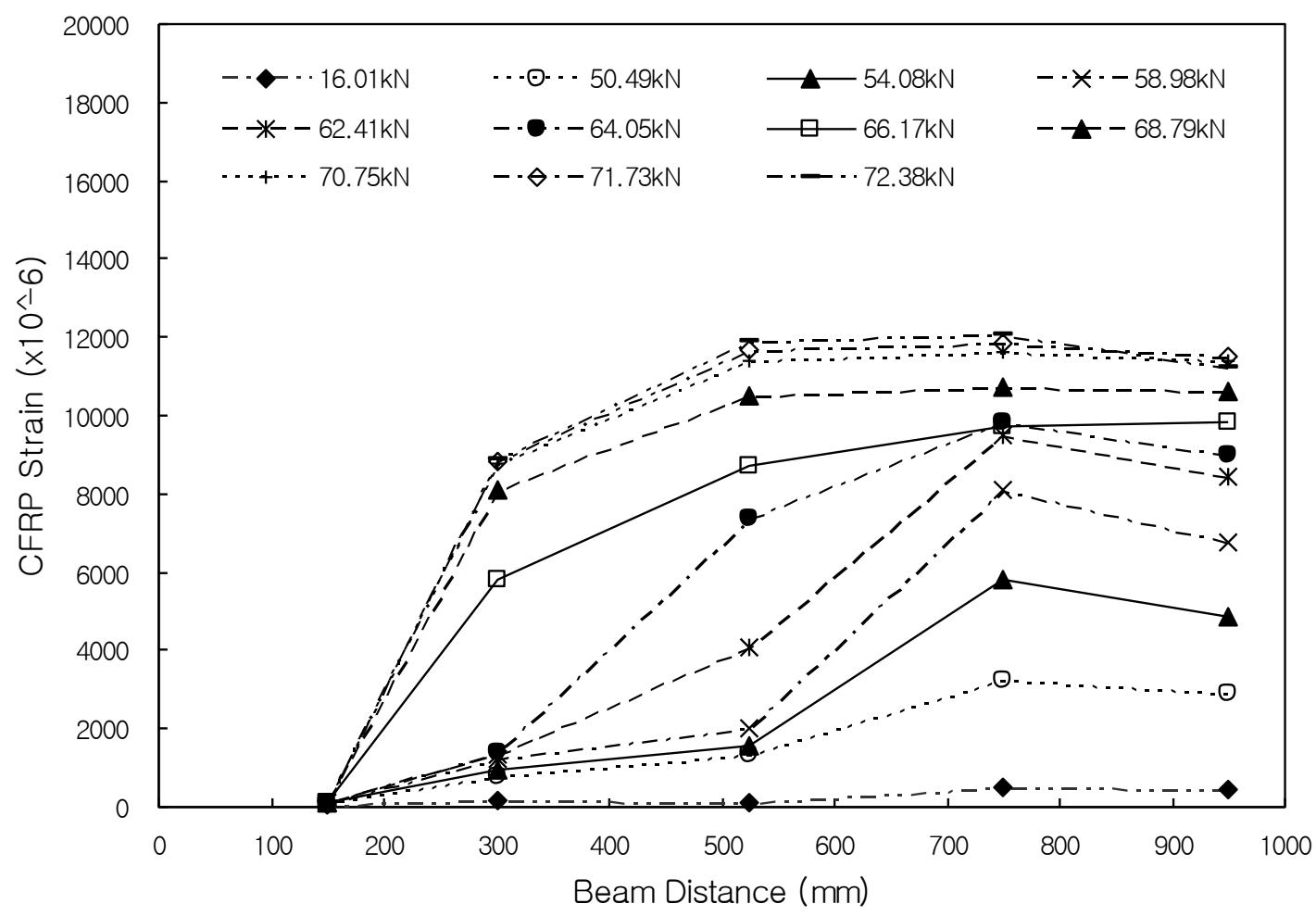

Figure 6. Load-CFRP Strain Distribution 


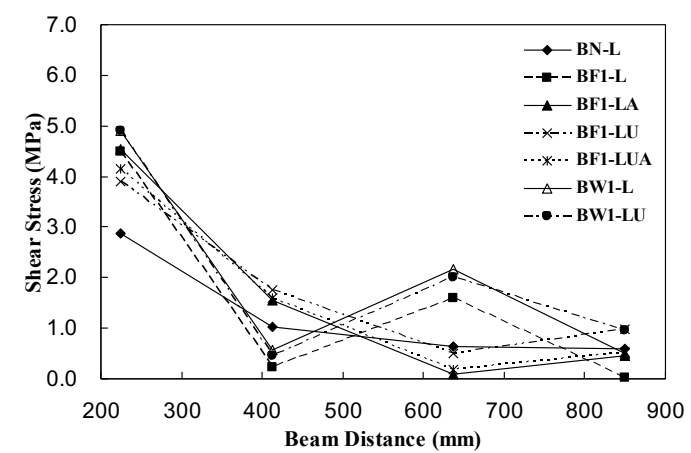

(a) BF1 Series Beams

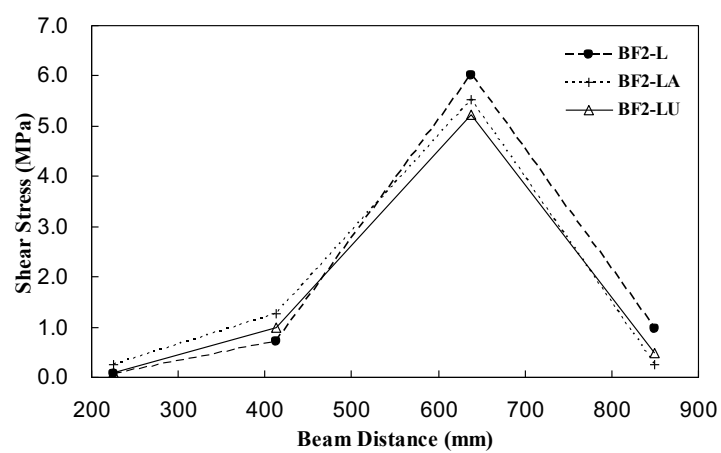

(b) BF2 Series Beams

Figure 7. Distribution of Interfacial Shear Stress 


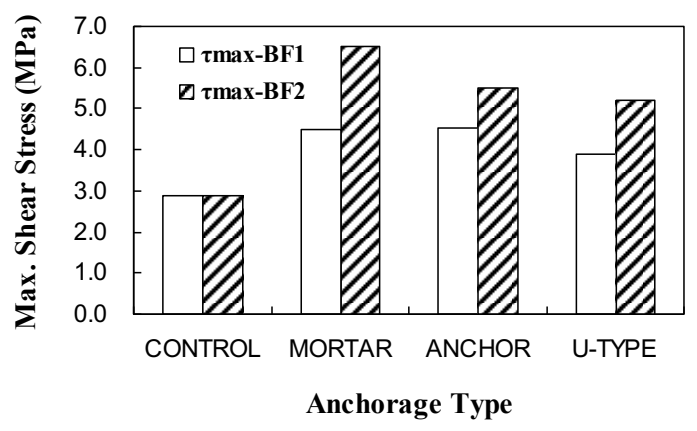

(a) Effect of Anchorage Type

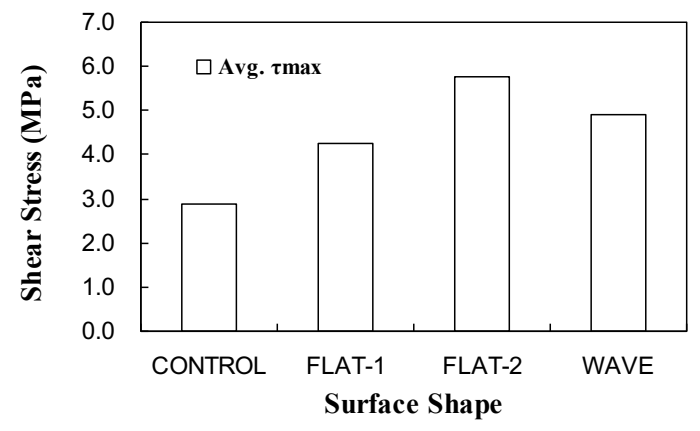

(b) Effect of Surface Shape

Figure 8. Effect of Anchorage and Surface Shape on the Interfacial Shear Stress 

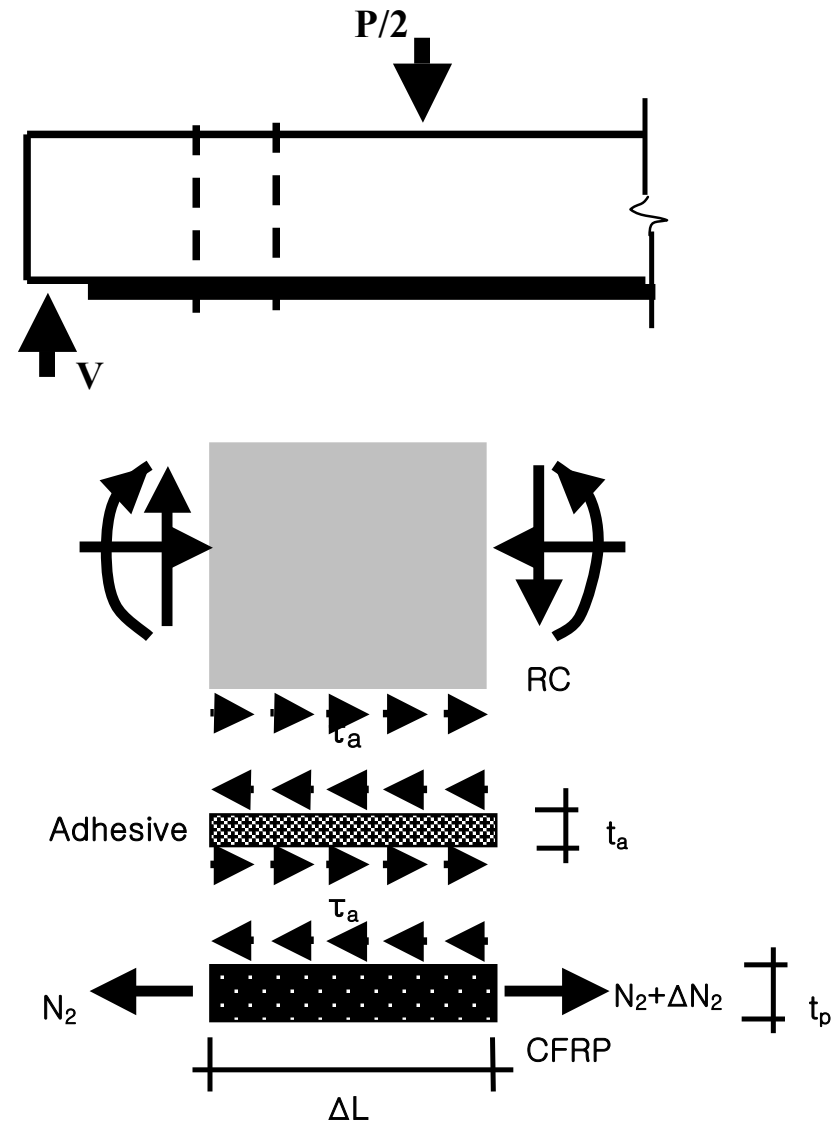

Figure 9. Resultant Forces and Stresses in Externally Strengthened RC Beam 